\title{
Contribution of Food for Work Program to Food Security of Selected Workers in Kapasia Upazila under Gazipur of Bangladesh
}

\author{
Shifat Sultana ${ }^{1}$, Md. Safiul Islam Afrad ${ }^{2}$ and Foyez Ahmed Prodhan ${ }^{2}$ \\ ${ }^{1}$ Training and Communication Division, Bangladesh Agricultural Research Institute, Gazipur-1701, \\ Bangladesh; ${ }^{2}$ Department of Agricultural Extension and Rural Development, Bangabandhu Sheikh \\ Mujibur Rahman Agricultural University (BSMRAU), Gazipur-1706, Bangladesh \\ *Corresponding author and Email:foyez_bsmrau@yahoo.com
}

Received: 11 March $2014 \quad$ Accepted: 13 December 2014

\begin{abstract}
The main focus of the study was to determine the food security status of the women involved in food for work program in terms of access to food (meals/day/person) and intake of energy (kilo calorie) and to explore the relationship between some selected characteristics of the beneficiaries with the changes in food security. The study was conducted in Kapasia upazila of Gazipur district during July 2013 to September 2013. Data were collected through pre-tested interview schedule. One hundred and ten women were selected following simple random sampling method. All of the family members of the respondents used to take three-meals/day when Food for Work Program (FFW) program was ongoing. More than four-fifth $(84.55 \%)$ of the household members received optimum to above optimum $\mathrm{kcal} / \mathrm{day}$ when FFW was running, but only three-fifth $(60.90 \%)$ of the respondents' family members took optimum to above optimum kcal/day when FFW program did not run. "Optimum level" and "above optimum level" calorie in taking family members increased by 12.73 percent and 10.91 percent, respectively when FFW program was running. The difference between per capita calorie intake by the respondents and their family members when FFW program was and was not running was found significant. Correlation analyses showed that annual income and credit facility had positive and significant relationship with contribution of FFW program on changes in food security status of the beneficiaries.
\end{abstract}

Keywords: Contribution, food for work program, food security

\section{Introduction}

Bangladesh is one of the most disaster-prone countries in the world. With a per capita gross domestic product (GDP) of \$597.49 in FY2012, Bangladesh is considered as a developing country (Anonymous, 2012). Considering that about 40 percent of the population is under the upper poverty line and 25 percent is below thepoverty line, 50 percent price increase in rice can significantly reduce the food intake of the poors. The government is therefore, faced with the challenge of strengthening its safety net programs to enable the poors and vulnerable population to cope with increases in food prices and to ensure adequate food supply (Alderman, 2002). The social safetynet is defined as "public interventions to assist individuals, households, and communities to better manage risk and to provide support to the critically poor" (World Bank, 2006). It simply aims at "raising the consumption of the poor through publicly provided transfer, but more recently the focus has shifted to 'helping low-income households cope with income fluctuation as well. 
Food for Work (FFW) social safetynets operate in rural aeras. The beneficiaries are generally women selected by Union Parishad who must be fit and willing to participate in the infrastructure related projects in the area. Population of Bangladesh is roughly divided into equal percentage of men and women. Women have great contribution to food security through participation in "Food for Work" social safetynet program. The work includes planting trees, digging canals, building embankments, developing ponds, road building and maintenance (Ahmed et al., 1995).

It is now important to understand the contribution of the "Food for Work" (FFW) program in relation to food security of the beneficiaries. In view of the above, the present study was undertaken to: (i) identify the socio economic characteristics of the respondents; ii) determine the food security status of the women involved in food for work program in terms of access to food (meals/day/person) and consumption of energy (calorie); and (iii) explore the relationship between some selected characteristics of the beneficiaries with the changes in food security status of the same.

\section{Methodology}

The study was conducted during July 2013 to September 2013 in Kapasia upazila under Gazipur district where Food for Work program for the selected women is going on. All of the 165 women involved in the Food for Work program was the target population of the study. Of them, 110 women were selected as sample of this study using simple random sampling technique and which was 66.6 percent of the population. In order to stockpile pertinent information, an interview schedule was prepared carefully keeping the objectives of the research in view.

Data were collected through face to face interview. Food security was measured on the basis of food consumption, access to food and calorie intake. The food consumption of the respondents was measured on the basis of their food needed for a month. The respondents were directly asked to mention the amount of food consumed per day along with the other members of her household. Access to food was measured on the basis of ability of meals/day by each of the family members. The respondents were directly asked to mention whether they were able to have three meals/day, two meals/day and one meal/day over a period (i.e., month) following Hossain (2009). Scores assigned were: 01 for taking 01 meal per day, 2 for 2 meals per day and 3 for 3 meals per day. To calculate the calorie values of the major foods item, a table of nutrient composition of Bangladeshi foods (Imai, 2003) were used which are shown in Table 1. Statistical measures like number, range, percent, mean, standard deviation and Pearson's correlation coefficient (r), and paired-t test analysis were used both for data evaluation and hypotheses testing by using SPSS program.

Table 1. Conversion factor of consumed food item energy (kcal)

\begin{tabular}{ll}
\hline Name of food item & Calorie contents ( Kcal/ kg) \\
\hline Rice & 3490 \\
Vegetables & 430 \\
Fish & 1360 \\
Meat & 1090 \\
Milk & 670 \\
Pulse & 3430 \\
Fruit & 200 \\
Edible oil & 9000 \\
\hline
\end{tabular}

Source: Imai (2003) 
Focus Group Discussion (FGD) was employed as the qualitative data collection method to triangulate the findings with quantitative data.

\section{Results and Discussion}

\subsection{Socio-economic characteristics of the respondents}

The socio-economic characteristics included age, education, family size, farm size, annual income, innovativeness and credit facility. Characteristics profile of the beneficiaries were determined and presented in Table 2. The findings indicated that most of the respondents were middle aged $(60.00 \%)$ and could sign only $(13.6 \%)$. It was also found that majority of them had small family size $(54.50 \%)$ and marginal farm size $(64.50 \%)$. Findings also indicated that most of them had medium level of innovativeness $(50.00 \%)$ and average credit facility (42.27).

Table 2. Distribution of the respondent according to their socio-economic characteristics

\begin{tabular}{|c|c|c|c|c|c|c|}
\hline Character & $\begin{array}{l}\text { Measuring } \\
\text { unit }\end{array}$ & Categories & $\begin{array}{l}\text { No. of } \\
\text { respondents }\end{array}$ & Percent & Mean & SD \\
\hline \multirow{3}{*}{ Age } & \multirow{3}{*}{ Actual year } & Young(up to 37 & 20 & 18.18 & \multirow{3}{*}{40.57} & \multirow{3}{*}{3.59} \\
\hline & & $\begin{array}{l}\text { Middle (38 to } 43 \\
\text { year) }\end{array}$ & 66 & 60.00 & & \\
\hline & & Old ( $>43$ year) & 24 & 21.82 & & \\
\hline \multirow[b]{2}{*}{ Education } & \multirow{2}{*}{ Scoring } & Illiterate (0) & 95 & 86.4 & & \\
\hline & & $\begin{array}{l}\text { Signature ability } \\
(0.5)\end{array}$ & 15 & 13.6 & 0.13 & 0.34 \\
\hline \multirow{3}{*}{ Family size } & \multirow{3}{*}{ Number } & Small (up to 4) & 60 & 54.5 & \multirow{3}{*}{4.5} & \multirow{3}{*}{1.5} \\
\hline & & Medium (5-7) & 32 & 29.1 & & \\
\hline & & Large (above 7) & 18 & 16.4 & & \\
\hline \multirow[b]{2}{*}{ Farm size } & \multirow{2}{*}{$\begin{array}{l}\text { Actual } \\
\text { (ha) }\end{array}$} & Landless & 38 & 34.5 & \multirow[b]{2}{*}{0.51} & \multirow[b]{2}{*}{0.22} \\
\hline & & $\begin{array}{l}\text { Marginal (0.021- } \\
0.6)\end{array}$ & 72 & 64.5 & & \\
\hline \multirow{3}{*}{ Annual income } & \multirow{3}{*}{ ‘000’ Tk. } & $\begin{array}{l}\text { Low ( up to } 6 \\
\text { thousand) }\end{array}$ & 25 & 22.73 & \multirow{3}{*}{11.22} & \multirow{3}{*}{4.25} \\
\hline & & $\begin{array}{l}\text { Medium ( } 6.1 \text { to } 10 \\
\text { thousand) }\end{array}$ & 46 & 41.82 & & \\
\hline & & $\begin{array}{l}\text { High ( above } 10 \\
\text { thousand) }\end{array}$ & 39 & 35.45 & & \\
\hline \multirow{3}{*}{ Innovativeness } & \multirow{3}{*}{ Scores } & Low (up to 5) & 43 & 39.10 & \multirow{3}{*}{11.45} & \multirow{3}{*}{4.07} \\
\hline & & Medium (6to 15) & 55 & 50.00 & & \\
\hline & & High $(>15)$ & 12 & 10.09 & & \\
\hline \multirow{4}{*}{ Credit facility } & \multirow{4}{*}{ '000' Tk. } & Never & 25 & 27.73 & \multirow{4}{*}{5.30} & \multirow{4}{*}{3.74} \\
\hline & & $\begin{array}{l}\text { Insufficient (1-5 } \\
\text { thousand) }\end{array}$ & 30 & 27.27 & & \\
\hline & & $\begin{array}{l}\text { Average (6-10 } \\
\text { thousand) }\end{array}$ & 52 & 42.27 & & \\
\hline & & $\begin{array}{l}\text { Sufficient ( }>10 \\
\text { thousand) }\end{array}$ & 3 & 2.73 & & \\
\hline
\end{tabular}




\subsection{Food security status as access to food}

The food security status as access to food (meals per day) was measured by number of full meals taken per day over the months of a year. As FFW program did not run all over the year, number of full meals taken per day was decreased when FFW was not in operation. Number of full meals taken by the family members/day is shown in Table 3.

Table 3 reveals that on an average, all of the family members of the respondents used to take three- meals/day when FFW program was running. However, when FFW program did not run, 70 percent of the family members of the respondents took three meals and about one-third $(30 \%)$ of the family members of the respondents took two meals/day.

\subsection{Food consumption of the respondent (calorie intake/day)}

Food consumption is one of the important factors for measuring the social development of a person. Usually, a person's income and health consciousness improve his/her food consumption behaviour in terms of consuming nutritious food. Food intake was measured as consumption of food items by respondents' households. The survey included eleven most essential food items like rice, pulses, vegetables, fruit, fish, meat, milk, and edible oil as presented in Table 4 with their calorie conversion. Table 4 shows the average food consumption by an individual member in $\mathrm{kg} / \mathrm{day} /$ person with an energy equivalent of $\mathrm{kcal} / \mathrm{day} /$ person when food for work program ran and did not run. As the respondents belonged to the below poor level, high calorie content food like meat, fish and oil intake by the respondents are below the optimum level. Only carbohydrate containing item like rice uptake is optimum. Some foods like fruit and milk are not taken by the respondents in regular basis.

Table 3. Distribution of the respondents based on number of meals taken per day

\begin{tabular}{lllll}
\hline \multirow{2}{*}{ Status of access to food } & \multicolumn{2}{l}{ When FFW runs } & \multicolumn{2}{l}{ When FFW does not run } \\
\cline { 2 - 5 } & $\begin{array}{l}\text { No. of } \\
\text { respondents }\end{array}$ & Percent & $\begin{array}{l}\text { No. of } \\
\text { respondents }\end{array}$ & Percent \\
\hline Three meals/day & 110 & 100 & 77 & 70 \\
Two meals/day & 00 & 00 & 33 & 30 \\
\hline
\end{tabular}

Table 4. Consumption of different food items by the respondents' household (kcal intake)

\begin{tabular}{|c|c|c|c|c|c|}
\hline \multirow{2}{*}{$\begin{array}{l}\text { Nature } \\
\text { of food } \\
\text { item }\end{array}$} & \multicolumn{2}{|c|}{$\begin{array}{c}\text { Average consumption by an } \\
\text { individual member (when FFW } \\
\text { runs) }\end{array}$} & \multicolumn{2}{|c|}{$\begin{array}{c}\text { Average consumption by an } \\
\text { individual member (when FFW does } \\
\text { not run) }\end{array}$} & \multirow[t]{2}{*}{$\begin{array}{l}\text { t-value df } \\
\quad(108)\end{array}$} \\
\hline & kg/day/person & $\mathrm{kcal} /$ day/person & kg/day/person & kcal/day/person & \\
\hline Rice & 0.381 & 1329.69 & 0.311 & 1085.39 & \\
\hline Pulse & 0.025 & 85.75 & 0.019 & 65.17 & \\
\hline Vegetables & 0.131 & 56.33 & 0.121 & 52.03 & \\
\hline Fruit & 0.017 & 3.4 & 0.012 & 2.4 & $9.19 * *$ \\
\hline Fish & 0.088 & 119.68 & 0.063 & 85.68 & \\
\hline Meat & 0.021 & 22.89 & 0.018 & 19.62 & \\
\hline Milk & 0.027 & 18.09 & 0.021 & 14.07 & \\
\hline Edible oil & 0.031 & 279 & 0.022 & 198 & \\
\hline Total & 0.721 & 1914.83 & 0.587 & 1522.36 & \\
\hline
\end{tabular}


Table 5. Distribution of the respondents according to their calorie intake

\begin{tabular}{lcccc}
\hline \multirow{2}{*}{ Categories } & \multicolumn{2}{c}{ When FFW runs } & \multicolumn{2}{c}{ When FFW does not run } \\
\cline { 2 - 5 } & No. & $\%$ & No. & $\%$ \\
\hline Below optimum (up to 1800 kcal/capita/day) & 17 & 15.45 & 43 & 39.09 \\
Optimum (>1800-2122 kcal/capita/day) & 76 & 69.10 & 62 & 56.36 \\
Above optimum (>2122 kcal/capita/day) & 17 & 15.45 & 5 & 4.54 \\
Total & 110 & 100 & 110 & 100 \\
\hline
\end{tabular}

The difference between per capita calorie intake by the respondents and their family members was tested employing paired t-test against the null hypothesis "There is no significant difference between calorie up take by the respondents when FFW runs and FFW does not run". The calculated t-value was 9.19 with 108 df which was significant at $0.01 \%$ level of probability. The difference is significant i.e. there is positive significant impact of FFW program on the calorie intake of the respondent women. Based on the calorie intake, the respondents were classified into three categories as done by Hossain (2009): 'below optimum' (upto1800 kcal/day/person), 'optimum' (>1800$2122 \mathrm{kcal} /$ day/person), and 'above optimum' (>2122 kcal/day/person). Distributions of respondents according to their calorie intake (per capita/day) are shown in Table 5.

Table 5 reveals that during running of FFW program, 69.10 percent of the respondents were found to take optimum level calorie, 15.45 percent of the household members had taken much below above optimum level calorie and 15.45 percent took below optimum level $\mathrm{kcal} /$ day. However, when FFW does not run 56.36 percent of the respondents were found to intake optimum level calorie, 39.09 percent of the household members had taken below optimum level calorie and only 4.54 percent took above optimum level kcal/day. Therefore, when FFW runs, more than four-fifth $(84.55 \%)$ of household members received optimum to above optimum $\mathrm{kcal} / \mathrm{day}$, whereas when the program does not run three-fifth $(60.90 \%)$ of the respondents' family members took optimum to above optimum $\mathrm{kcal} / \mathrm{day}$. This indicates that there is an increase in calorie uptake by the respondents' household members when FFW runs.

\subsection{Change in food security status as measured by calorie intake}

Change in food security status as measured by calorie intake per person per day. Effort has been made to measure calorie intake by the respondents' family members both 'when FFW program runs' and 'when FFW program does not run'. Changes in food security status according to their calorie intake (per capita/day) in 'when FFW program runs' and 'when FFW program does not run' are shown in Figure 1.

Figure 1 reveals that percentage of the "optimum level"and "above optimum level" calorie intaker respondents' family members increased by 12.73 percent and 10.91 percent respectively when FFW program runs whereas "below optimum level" calorie intake household members decreased by 23.64 percent. From the results, it can be concluded that Food for Work program exerts positive influence to change in food security status of the beneficiaries.

\subsection{The relationship between selected characteristics of the beneficiaries and their changes in food security status}

For exploring the relationship between selected characteristics of the respondents and their changes in food security status, correlation analysis was employed (at 1 and 5\% level of significance) for testing the hypotheses. The results of correlation analysis are shown in Table 6. 


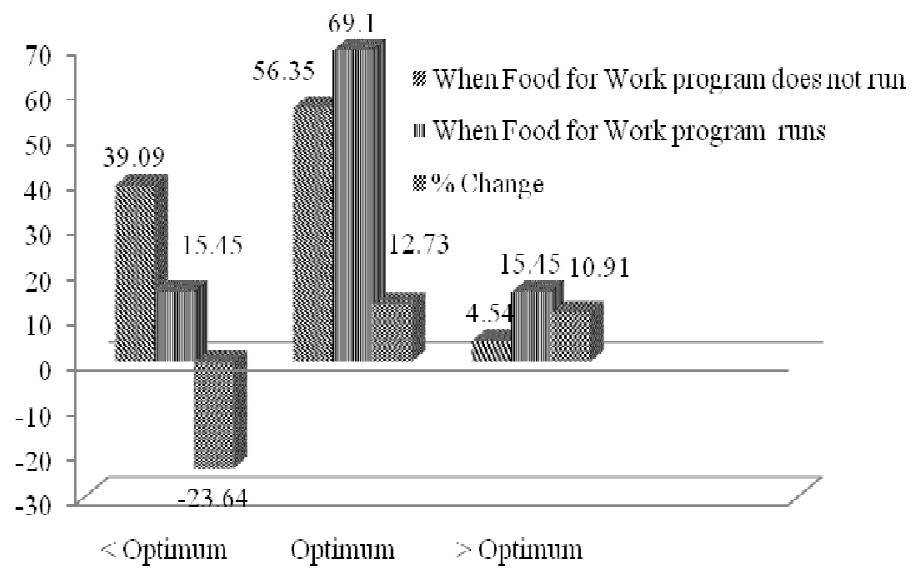

Figure 1. Change in food security status as measured by calorie intake per person per day

Table 6. Relationship between Changes in food security status and selected characteristics of the respondents

\begin{tabular}{|c|c|c|}
\hline Selected characteristics & Dependent variable & Coefficient of Correlation (r) \\
\hline Age & & $0.112^{\text {(NS) }}$ \\
\hline Education & & $0.017^{(\mathrm{NS})}$ \\
\hline Family size & & $-0.154^{*}$ \\
\hline Annual income & Changes in food security status & $0.242^{* *}$ \\
\hline Farm size & & $0.07^{(\mathrm{NS})}$ \\
\hline Innovativeness & & $0.067^{(\mathrm{NS})}$ \\
\hline Credit facility & & $0.626^{* *}$ \\
\hline
\end{tabular}

$* *=$ Significant at $1 \%$ level, $*=$ Significant at $5 \%$ level, NS $=$ Not significant

Findings shown in Table 6 indicate that age, education and organizational participation were not an important indicator concerning the contribution of FFW program towards household food security. Miah et al. (2010) found that education has no effect on food security among indigenous people. Family size was significantly and negatively correlated implying that food security increase with the decreasing number of family members that means, larger family size and presence of high dependent members in household worsen the food security status of households. As the amount of calorie needed by the family increases with the increase of the number of family members, hence, the contribution of the FFW program to household food security was, of course, decreased with the increase of family requirements. This finding is consistent with the result found by Miah et al. (2010) and Kobir (2007). On the other hand, annual income and credit facility were positively and significantly correlated with contribution of FFW program towards household food security (Table 6). Higher annual family income and credit facility make the individual more powerful to take any decision and capable to increase their purchase capacity and also increase food security. This finding is consistent with that reported by FAO (2002), Miah et al. (2010) and Kobir (2007). 
Table 7. Change in food security status and socioeconomic aspects of the beneficiaries $(n=13)$

\begin{tabular}{|c|c|c|}
\hline Areas & Extent of changes & Reasons for changes \\
\hline Socioeconomic aspects & Medium & $\begin{array}{ll}\text { - } & \text { Ensured monthly wage } \\
\text { - } & \text { Minimum risk compared to business } \\
\text { - } & \text { Wages are sufficient for taking three } \\
\text { - } & \text { Heals/day } \\
\text { - High job Satisfaction }\end{array}$ \\
\hline
\end{tabular}

Table 8. Problems related to the FFW and their probable solutions

\begin{tabular}{|c|c|c|}
\hline Sl. No. & Problem statements & Probable solutions \\
\hline 1. & Medical facilities are not available. & $\begin{array}{l}\text { - Medical facilities should be provided in } \\
\text { case of emergency. }\end{array}$ \\
\hline 2. & $\begin{array}{l}\text { Mental harassment due to } \\
\text { irresponsibility of supervisor }\end{array}$ & - Supervisor inspection should be timely. \\
\hline 3. & Short time working opportunity & - $\quad$ Program should be extended for long time. \\
\hline
\end{tabular}

\subsection{Change in food security status and socioeconomic aspects of the beneficiaries $(n=13)$}

Qualitative information presented in Table 7 indicate that the food security status of the respondent participants have been changed highly because they get regular monthly wage during the running of FFW program activities. Again, socioeconomic aspects of the beneficiaries have also changed to a medium level due to their high job satisfaction towards this FFW program.

\subsection{Probable solutions of the problems related to the participation in the food for work program $(n=13)$}

The suggestions provided by the focus group discussants have been presented in Table 8. The participants in the FGD showed their concerns about the solutions of the problems in connection with the FFW program.

\section{Conclusions}

Based on the findings of the study, it can be concluded that all the family members of the respondents used to take three-meals/day when
FFW program runs. The difference between per capita calorie intake by the respondents and their family members when FFW program runs and when FFW program does not run was found significant. More than four-fifth of household members received "optimum to above optimum" $\mathrm{kcal} /$ day when FFW program runs, whereas when FFW program does not runs three-fifth of the respondents' family members took "optimum" to "above optimum" kcal/day.

Qualitative findings indicate that the food security status of the participants have been changed highly because they get regular monthly wage during the running of FFW program activities. Major problems identified by the FGD members were no medical facilities, mental harassment due to irresponsibility of supervisor and short time working opportunity in the program. Thus, to increase the food security and socio-economic aspects of the beneficiaries, food/cash provided for the FFW program should be increased to ensure optimum level of calorie intake by the household members of the beneficiaries. There should also be provision for medical facilities in case of emergency and timely supervisory inspection by the supervisors and extension of the program for longer time. 


\section{References}

Alderman, H. 2002. "Subsidies as a Social Safety Net: Effectiveness and Challenges." The World Bank, Washington, USA.

Anonymous, 2012. Bangladesh GDP Growth rate. Available at: http://www.tradingeconomics.com/bangladesh/gdp-growth

Ahmed, A. U., Zohir, S., Kumar, S. K. and Chowdhury, O. H. 1995. Bangladesh's Food-For Work Program and Alternatives to Improve Food Security. In: Employment for Poverty Alleviation and Food Security, (ed.) J. von Braun, Washington DC, USA: International Food Policy Research Institute.

BBS 2012. Statistical Yearbook of Bangladesh. Bangladesh Bureau of Statistics, Statistics Division, Ministry of Planning, Government of the Peoples' Republic of Bangladesh, Dhaka.

FAO 2002. The State of Food Insecurity in the World 2001. Rome. 4-7 pp.

Hossain, M. A. 2009. Impact of Food Security Project of the Department of Agricultural Extension on the Livelihood and Food
Security Status of the Beneficiaries. PhD (Agril. Ext. and Rural Dev.)Thesis, Bangabandhu Sheikh Mujibur Rahman Agricultural University. Gazipur.

Imai, S. 2003. Livelihood Survey Forms, SPFS, FAO. Bangladesh. Asia Pacific Journal of Environment and Development, 4(1):76

Islam M., 2000. "Women Look Forward"; Bangladesh in the New Millennium, Community Development Library.

Kobir, H. 2007. Contribution of Farming Enterprises of the Small Farmers towards Household Food Security. MS Thesis. Department of Agricultural Extension Education. Bangladesh Agricultural University, Mymensingh.

Miah, M. A. M., Alam, Q. M., Ullah, M. M. and Hossain, M. S. 2010. Household Food Security among Indigenous Hill People in Khagrachari District of Bangladesh. Annual Research Report (2009-2010), BARI, Gazipur-1701.

World Bank. 2006. Social Safety Nets in Bangladesh: An Assessment. Bangladesh Development Series-Paper No. 9. Dhaka. 